\title{
Retrofitting as an environmental hybrid approach (EHA) in conservation works on historical buildings in Malaysia
}

\begin{abstract}
Historical buildings bring out the symbols of history, memories, social and culture of a place as well as representing the economic standard of the local people. It can be seen from the architecture style of the building, size and material used. That is why it is very important for us to preserve and conserve it not only for countyôs heritage and legacy but also making them as tourist attractions. Therefore, this paper is aim to identify the potential of retrofitting mechanism as Environmental Hybrid Approach (EHA) in conservation works on the historical buildings as well as to investigate students perception on retrofitting mechanism. Triangulation methods were used for this research. Retrofitting means fitting in new mechanism that was not installed during first construction. It can be adapted as crossintegrated mechanism and can be use in architecture sector. By retrofitting, the vacant historical building can be reused back for new purpose such as an office or theater that can be use to generate income while maintaining the historical values of the original historical building. Practically, this method also brings positive impact to the environment. Retrofitting is consider as an Environmental Hybrid Approach (EHA) in conservation works of historical buildings due to the facts that it use less new materials for new construction by reuse and reenhancement back original material from historical building, reduce the production of construction waste thus minimizing negative impact to the environment. Retrofitting mechanism also undergo shorten construction period, hence it use less energy, less construction workers on-site and able to reduce the total cost construction compare to conventional construction.
\end{abstract}

Keyword: Retrofitting; Historical building; Preserve; Maintaining; Reused 